\title{
PENGARUH APLIKASI BEBERAPA KONSENTRASI FORMULASI KERING JAMUR Beauveria bassiana (Bals.) Vuill. ISOLAT TEGINENENG TERHADAP MORTALITAS HAMA PENGISAP BUAH KAKAO (Helopeltis spp.) DI LABORATORIUM
}

\author{
G.A Oka Dwipayana, Purnomo*, Lestari Wibowo \& Indriyati \\ Jurusan Agroteknologi, Fakultas Pertanian Universitas Lampung \\ J1.Prof. Soemantri Brodjonegoro, No.1, Bandar Lampung 35145 \\ E-mail: gaoka.dwipayana@yahoo.com \\ * Korespondensi, E-mail: purjomo@yahoo.com
}

\begin{abstract}
ABSTRAK
Pemanfaatan musuh alami sebagai agensia pengendali hayati mempunyai beberapa keuntungan seperti mencegah resistensi hama, biaya relatif murah dan aman bagi lingkungan. Salah satu musuh alami yang dapat digunakan untuk mengendalikan hama adalah jamur B. bassiana. Jamur B. bassiana dapat dibuat dalam bentuk formulasi kering. Keuntungan dari formulasi kering ini diantaranya dapat disimpan dalam jangka waktu yang lama, praktis, dan mudah diaplikasikan. Penelitian ini bertujuan untuk menguji pengaruh beberapa konsentrasi formulasi kering jamur B. bassiana isolat Tegineneng terhadap mortalitas hama pengisap buah kakao (Helopeltis spp.). Pengujian dilakukan di laboratorium menggunakan enam perlakuan yaitu kontrol (aplikasi air steril), aplikasi formulasi kering berbahan aktif jamur B. bassiana dengan taraf konsentrasi $5 \mathrm{~g} \mathrm{l}^{-1}, 10 \mathrm{~g} \mathrm{l}^{-1}, 15 \mathrm{~g} \mathrm{l}^{-}$ ${ }^{1}, 20 \mathrm{~g} \mathrm{l}^{-1}$ dan $25 \mathrm{~g} \mathrm{l}^{-1}$ air. Percobaan ini disusun menggunakan Rancangan Acak Kelompok (RAK). Pengelompokan berdasarkan 3 waktu aplikasi yang berbeda. Serangga uji yang digunakan adalah pengisap buah kakao (Helopeltis spp.). Data yang didapatkan dianalisis ragam dan dilanjutkan dengan Uji BNT dengan taraf nyata 5\%. Hasil penelitian menunjukkan bahwa jamur B. bassiana isolat Tegineneng yang dibuat dalam bentuk formulasi kering mampu menyebabkan kematian terhadap serangga uji pengisap buah kakao (Helopeltis spp.). Mortalitas Helopeltis spp. tertinggi terdapat pada perlakuan $25 \mathrm{~g} \mathrm{l}^{-1}$ air formulasi kering jamur B. bassiana isolat Tegineneng sebesar 63,33\%.
\end{abstract}

Kata kunci : Beauveria bassiana, formulasi kering, mortalitas, Helopeltis spp.

\section{PENDAHULUAN}

Kakao merupakan komoditas perkebunan yang peranannya cukup penting bagi perekonomian nasional, khususnya sebagai penyedia lapangan kerja dan sumber pendapatan negara, namun dalam budidaya kakao terdapat berbagai kendala. Menurut Suparno (2001), salah satu kendala yang dihadapi dalam budidaya kakao adalah serangan hama. Salah satu hama penting pada tanaman kakao adalah pengisap buah kakao (Helopeltis spp.).

Menurut Sulistyowati \& Sardjono (1988 dalam Amini, 2011), hama pengisap buah kakao (Helopeltis spp.) menimbulkan kerusakan dengan cara menusuk dan menghisap cairan buah maupun tunas-tunas muda. Serangan pada buah muda menyebabkan matinya buah, sedangkan serangan pada buah berumur sedang menyebabkan terbentuknya buah abnormal, akibatnya hasil dan mutu kakao menurun karena biji yang dihasilkan berukuran kecil. Selain menyerang buah, Helopeltis spp. juga menyerang tunas-tunas muda atau pucuk, yang mengakibatkan mati pucuk (die-back). Serangan berat dan berulang pada buah dan pucuk dapat menyebabkan penurunan produksi kakao sekitar 36-75\%.

Untuk mendukung pengembangan metode pengendalian hama yang berwawasan lingkungan, diperlukan kajian tentang peranan musuh alami sebagai agensia untuk mengendalikan hama. Salah satu agensia hayati yang potensial sebagai sarana pengendalian hama adalah jamur Beauveria bassiana (Indriyati, 2009).

Menurut hasil penelitian Yulyanti (2012), jamur B. bassiana isolat Tegineneng menyebabkan mortalitas Helopeltis spp. yang lebih tinggi dibandingkan dengan isolat lain seperti UGM, Trimurjo, Gading rejo dan Bantul. Jamur B. bassiana isolat Tegineneng menyebabkan mortalitas sebesar $67,50 \%$. Hal ini diduga dipengaruhi oleh kerapatan dan viabilitas spora yang tinggi dari jamur $B$. bassiana isolat Tegineneng.

Jamur B. bassiana dapat dibuat dalam bentuk formulasi kering. Keuntungan dari jamur entomopatogen yang dibuat dalam bentuk formulasi kering ini diantaranya adalah dapat disimpan dalam jangka waktu yang lama, praktis, dan mudah diaplikasikan. Berdasarkan uraian di atas maka perlu dibuat formulasi 
kering dari jamur B. bassiana isolat Tegineneng beserta pengujian formulasi kering tersebut dalam menimbulkan mortalitas terhadap hama pengisap buah kakao (Helopeltis spp.).

Penelitian ini bertujuan untuk menguji pengaruh aplikasi beberapa konsentrasi formulasi kering jamur B. bassiana isolat Tegineneng terhadap mortalitas hama pengisap buah kakao (Helopeltis spp.) di laboratorium.

\section{METODE PENELITIAN}

Penelitian ini dilakukan pada bulan September 2012 sampai Februari 2013, di Laboratorium Hama Tumbuhan Fakultas Pertanian Universitas Lampung. Percobaan disusun dalam Rancangan Acak Kelompok yang terdiri atas 6 perlakuan. Setiap perlakuan terdiri dari 3 kelompok waktu aplikasi yang berbeda. Setiap satu satuan percobaan terdiri dari 20 ekor imago Helopeltis spp. yang diaplikasikan dengan beberapa taraf konsentrasi formulasi kering jamur B. bassiana. Perlakuan terdiri atas air steril sebagai kontrol (P0), aplikasi formulasi kering jamur $B$. bassiana konsentrasi $5 \mathrm{~g}^{-1}$ air (P1), aplikasi formulasi kering jamur $B$. bassiana konsentrasi $10 \mathrm{~g} \mathrm{l}^{-1}$ air (P2), aplikasi formulasi kering jamur B. bassiana konsentrasi $15 \mathrm{~g} \mathrm{l}^{-1}$ air (P3), aplikasi formulasi kering jamur $B$. bassiana konsentrasi $20 \mathrm{~g} \mathrm{l}^{-1}$ air (P4) dan aplikasi formulasi kering jamur $B$. bassiana konsentrasi $25 \mathrm{~g} \mathrm{l}^{-1}$ air (P5). Data yang didapatkan dianalisis ragam dan dilanjutkan dengan $\mathrm{Uji}$ BNT dengan taraf nyata 5\% kemudian dilakukan analisis Probit untuk menentukan $\mathrm{LC}_{50}$.

Pembiakan serangga dilakukan di laboratorium dengan menggunakan inang alternatif yaitu buah mentimun. Sebelum pembiakan terlebih dahulu dilakukan pencarian indukan Helopeltis spp. Indukan serangga terdiri dari imago dan nimfa Helopeltis spp. yang diambil dari pertanaman kakao di daerah Brenung, Gedongtataan. Serangga imago dan nimfa dipisahkan dan dimasukkan ke dalam toples plastik yang sudah diberi pakan buah mentimun di dalamnya dan ditutup menggunakan kain strimin yang diikat menggunakan karet gelang. Setiap toples diisi \pm 20 ekor serangga dan 2 buah mentimun. Pakan diganti setiap 2-3 hari sekali. Setelah imago bertelur, buah mentimun yang digunakan sebagai media bertelur \pm 4 buah dipisahkan dan ditempatkan pada toples yang baru, ditutup dan diberi label tanggal. Setelah telur menetas, maka nimfa dipindahkan ke dalam toples yang baru dan diberi buah mentimun yang masih segar. Begitu seterusnya sampai diperoleh jumlah yang diperlukan.

Isolat jamur B. bassiana yang digunakan dalam penelitian ini berasal dari Tegineneng, kemudian dilakukan isolasi guna mempertahankan dan memperbanyak isolat murni. Isolasi dilakukan dengan menggunakan media SDA (Sabouraud dextrose agar), lalu diinkubasi selama \pm 3 minggu. Setelah itu, jamur siap digunakan untuk ditumbuhkan pada media beras yang kemudian akan diproses lebih lanjut menjadi formulasi kering.

Pembuatan media beras dilakukan dengan cara mencuci beras sampai bersih kemudian beras dikukus hingga setengah matang (10 menit). Setelah itu diangkat dan dimasukkan dalam kantong plastik tahan panas lalu bagian atas plastik yang tidak terisi dirapikan, digulung dan diikat menggunakan karet gelang. Beras disterilkan dengan autoklaf pada suhu $120^{\circ} \mathrm{C}$ selama 20 menit, lalu beras diangkat dan dikeringanginkan.

Perbanyakan jamur B. bassiana pada media beras dilakukan dengan inokulasi jamur $B$. bassiana pada media beras yang telah steril dan dikeringanginkan sebelumnya. Kantong plastik berisi beras yang sudah diinokulsi dengan jamur B. bassiana kemudian diberi udara dan diikat dengan karet gelang lalu diinkubasi selama 2 minggu.

Teknik pembuatan formulasi kering jamur $B$. Bassiana dalam penelitian ini mengacu pada metode yang telah dilakukan oleh Purnomo et al. (2012). Pembuatan formulasi kering dimulai dengan mengeringkan jamur $B$. bassiana yang tumbuh pada media beras setelah melewati masa inkubasi 2 minggu. Pengeringan dilakukan di dalam lemari pendingin pada suhu $5^{\circ} \mathrm{C}$ selama 12 hari. Setelah kering lalu dihaluskan dengan cara diblender dan diayak sehingga menjadi tepung biomassa spora. Bahan pembawa seperti tepung jagung, kaolin dan zeolit disterilkan terlebih dahulu menggunakan oven pada suhu $80^{\circ} \mathrm{C}$ selama 2 jam. Setelah itu tepung biomasa spora dan bahan pembawa ditimbang sesuai dengan jumlah yang telah ditentukan lalu dicampur di dalam satu kantung plastik (Tabel 1). Setelah formulasi diperoleh, dilakukan penghitungan jumlah spora sehingga diketahui kerapatan spora atau jumlah spora dalam $1 \mathrm{ml}$ suspensi. Untuk mengetahui kandungan sporanya, diambil $1 \mathrm{~g}$ formulasi kering $B$. bassiana isolat Tegineneng yang berupa bubuk halus dan dimasukkan ke dalam $10 \mathrm{ml}$ aquades, dihomogenkan dengan rotamixer, kemudian dilakukan pengenceran sampai $10^{-3}$ lalu dihitung jumlah sporanya dengan bantuan alat Haemocytometer. Hasil penghitungan menunjukkan kerapatan spora formulasi kering jamur B. bassiana isolat Tegineneng sebesar 2,85 $\times 10^{6} \mathrm{ml}^{-1}$. Pengujian formulasi kering berbahan aktif jamur $B$. bassiana dilakukan dengan cara melarutkan formulasi kering dengan air. Setelah itu ditambahkan bahan perata perekat (indostick) sebanyak $1 \mathrm{ml}^{1^{-1}}$. Untuk 
Tabel 1. Komposisi formulasi kering jamur B. bassiana

\begin{tabular}{lc}
\hline Bahan & Jumlah $(\mathrm{g})$ \\
\hline Tepung biomassa spora & 40 \\
Kaolin & 20 \\
Zeolit & 20 \\
Tepung jagung & 20 \\
\hline Total & 100 \\
\hline
\end{tabular}

menentukan konsentrasi formulasi kering jamur $B$. bassiana yang digunakan untuk uji utama terlebih dahulu dilakukan uji pendahuluan. Berdasarkan uji pendahuluan tersebut ditentukan taraf konsentrasi mulai dari $5 \mathrm{~g} \mathrm{l}^{-1}$, $10 \mathrm{~g} \mathrm{l}^{-1}, 15 \mathrm{~g} \mathrm{l}^{-1}, 20 \mathrm{~g} \mathrm{l}^{-1}$ dan $25 \mathrm{~g} \mathrm{l}^{-1}$ air formulasi kering berbahan aktif jamur B. bassiana. Pelaksanaan pengujian formulasi kering dilakukan dengan memasukkan 20 ekor imago Helopeltis spp. per satu satuan percobaan ke dalam botol air mineral yang dipotong bagian atas dan bagian bawahnya. Setelah itu pada bagian bawah botol tersebut ditutup dengan kain strimin dan diikat dengan karet gelang. Formulasi kering yang sudah dicampur dengan air dan bahan perekat diaplikasikan menggunakan handsprayer sesuai dengan tingkat dosis yang telah ditentukan. Selanjutnya serangga yang sudah diaplikasikan dimasukkan kembali ke dalam toples dan diberi pakan mentimun. Pengamatan jumlah Helopeltis spp. yang mati akibat terinfeksi jamur B. bassiana dilakukan setiap 24 jam sekali selama 10 hari setelah aplikasi. Menurut Wahyono et al. (2007) bahwa mortalitas serangga dapat dihitung menggunakan rumus seperti berikut :

$$
M=\frac{n}{N} \times 100 \%
$$

dengan $\mathrm{M}$ adalah mortalitas serangga (\%), $\mathrm{n}$ adalah serangga yang mati (ekor), dan $\mathrm{N}$ adalah jumlah serangga yang diuji (ekor)

Selain menghitung persentase mortalitas Helopeltis spp. dilakukan juga pengitungan periode letal. Periode letal adalah jangka waktu sejak inokulasi sampai terjadinya kematian. Periode letal dihitung dengan rumus (Susilo et al.,1993 dalam Indriyati, 2009):

$$
\text { Periode Letal }(\mathrm{T})=\left[\sum\left(\mathrm{H}_{\mathrm{i}} \times \mathrm{M}_{\mathrm{i}}\right)\right] /\left[\sum\left(\mathrm{M}_{\mathrm{i}}\right)\right]
$$

dengan $\mathrm{F}$ adalah periode letal, Hi adalah hari ke-, dan Mi adalah jumlah serangga mati (ekor) karena terinfeksi jamur B. bassiana

\section{HASIL DAN PEMBAHASAN}

Hasil percobaan menunjukkan bahwa aplikasi formulasi kering jamur $B$. bassiana isolat Tegineneng dapat menyebabkan mortalitas Helopeltis spp. Hal ini ditunjukkan dari hasil pengamatan sejak 1 hsa (Tabel 2). Pada pengamatan 2 hsa mortalitas Helopeltis spp. tertinggi sebesar $15 \%$ terdapat pada aplikasi formulasi kering jamur B. bassiana konsentrasi $20 \mathrm{~g} \mathrm{l}^{-1}$ air, namun tidak berbeda dengan mortalitas pada perlakuan $10 \mathrm{~g} \mathrm{l}^{-}$ 1, $15 \mathrm{~g} \mathrm{l}^{-1}$, dan $25 \mathrm{~g} \mathrm{l}^{-1}$ air sebesar 13,33\%. Pada pengamatan 8 hsa mortalitas Helopeltis spp. tertinggi terdapat pada aplikasi formulasi kering jamur $B$. bassiana konsentrasi $25 \mathrm{~g} \mathrm{l}^{-1}$ air sebesar 63,33\%. Persentase mortalitas tersebut lebih tinggi jika dibandingkan dengan perlakuan lain yang konsentrasinya lebih rendah. Nilai mortalitas terendah terdapat pada aplikasi formulasi kering jamur $B$. bassiana dengan konsentrasi $5 \mathrm{~g} \mathrm{l}^{-1}$ air yang menyebabkan mortalitas Helopeltis spp. sebesar $25 \%$.

Pada tabel 2 dapat dilihat bahwa semakin tinggi konsentrasi formulasi kering jamur B. bassiana yang diaplikasikan semakin tinggi pula persentase mortalitas Helopeltis spp. Hal ini serupa dengan pernyataan Ferron (1981 dalam Atmadja et al., 2010), yang menyatakan bahwa semakin tinggi konsentrasi maka semakin banyak spora yang terkandung di dalamnya. Jumlah spora yang banyak itu akan menyebabkan perkembangan jamur makin cepat dan daya infeksinya makin tinggi.

Hasil pengamatan menunjukkan bahwa Helopeltis spp. yang terinfeksi jamur B. bassiana menunjukkan gejala awal seperti berkurangmya aktivitas gerak dan aktivitas makan, selanjunya Helopeltis spp. akan mengalami kematian. Menurut Thomas et al. (1987 dalam Deciyanto, 2007) kematian serangga biasanya disebabkan oleh kerusakan jaringan secara menyeluruh, karena toksin yang diproduksi oleh $B$. bassiana yang disebut beauvericin. Apabila Helopeltis 
spp. yang mati ditempatkan pada tempat lembab seperti cawan petri yang diberi tisu basah maka pada tubuh Helopeltis spp. akan ditumbuhi oleh miselia jamur $B$. bassiana yang berwarna putih.

Hasil pengamatan menunjukkan bahwa periode letal atau waktu yang dibutuhkan jamur B. bassiana isolat Tegineneng untuk menyebabkan kematian pada serangga uji Helopeltis spp. tidak berbeda pada seluruh perlakuan, berkisar antara 3,84 hari sampai 4,45 hari setelah aplikasi (Tabel 3).

Analisis probit digunakan untuk mendapatkan nilai $\mathrm{LC}_{50}$, yaitu suatu konsentrasi yang dapat menyebabkan kematian $50 \%$ pada serangga hama yang diuji (Moekasan, 1993 dalam Negara, 2003). Berdasarkan hasil analisis probit nilai $\mathrm{LC}_{50}$ dari formulasi kering jamur B. bassiana terhadap mortalitas Helopeltis spp. pada 8 hsa adalah pada konsentrasi $22,57 \mathrm{~g} \mathrm{l}^{-1}$ air. Hal ini berarti pada aplikasi formulasi kering jamur dengan konsentrasi 22,57 $\mathrm{g} \mathrm{l}^{-1}$ air dapat menyebabkan kematian Helopeltis spp. sebesar $50 \%$.

Dari hasil penelitian ini terlihat bahwa jamur $B$. bassiana yang dibuat dalam bentuk formulasi kering mampu menyebabkan kematian terhadap serangga uji Helopeltis spp. Formulasi kering dalam penelitian ini mudah dibuat, praktis dan mudah diaplikasikan sehingga berpotensi untuk digunakan dan dikembangkan di tingkat petani.

Tabel 2. Persentase mortalitas Helopeltis spp. setelah aplikasi formulasi kering jamur B. bassiana isolat Tegineneng

\begin{tabular}{lcccccccc}
\hline \multirow{2}{*}{ Perlakuan } & \multicolumn{7}{c}{ Mortalitas Helopeltis spp. (\%) pada } \\
\cline { 2 - 9 } & 1 hsa & 2 hsa & $3 \mathrm{hsa}$ & $4 \mathrm{hsa}$ & $5 \mathrm{hsa}$ & $6 \mathrm{hsa}$ & $7 \mathrm{hsa}$ & $8 \mathrm{hsa}$ \\
\hline P0 & 0,00 & $0,00 \mathrm{a}$ & $1,66 \mathrm{a}$ & $5,00 \mathrm{a}$ & $10,00 \mathrm{a}$ & $10,00 \mathrm{a}$ & $10,00 \mathrm{a}$ & $10,00 \mathrm{a}$ \\
P1 & 0,00 & $1,66 \mathrm{a}$ & $8,33 \mathrm{~b}$ & $10,00 \mathrm{ab}$ & $16,66 \mathrm{ab}$ & $25,00 \mathrm{~b}$ & $25,00 \mathrm{~b}$ & $25,00 \mathrm{~b}$ \\
P2 & 3,33 & $13,33 \mathrm{~b}$ & $16,66 \mathrm{c}$ & $18,33 \mathrm{bc}$ & $23,33 \mathrm{bc}$ & $26,66 \mathrm{bc}$ & $30,00 \mathrm{bc}$ & $31,66 \mathrm{bc}$ \\
P3 & 5,00 & $13,33 \mathrm{~b}$ & $20,00 \mathrm{~cd}$ & $25,00 \mathrm{~cd}$ & $30,00 \mathrm{~cd}$ & $33,33 \mathrm{~cd}$ & $40,00 \mathrm{~cd}$ & $40,00 \mathrm{~cd}$ \\
P4 & 3,33 & $15,00 \mathrm{~b}$ & $23,33 \mathrm{de}$ & $26,66 \mathrm{de}$ & $33,33 \mathrm{de}$ & $41,66 \mathrm{de}$ & $46,66 \mathrm{de}$ & $50,00 \mathrm{~d}$ \\
P5 & 6,66 & $13,33 \mathrm{~b}$ & $26,66 \mathrm{e}$ & $35,00 \mathrm{e}$ & $43,33 \mathrm{e}$ & $48,33 \mathrm{e}$ & $58,33 \mathrm{e}$ & $63,33 \mathrm{e}$ \\
\hline F hit & $1,63 \mathrm{tn}$ & $11,09 *$ & $27,48^{*}$ & $15,35^{*}$ & $7,74 *$ & $9,94 *$ & $17,12^{*}$ & $21,89 *$ \\
\hline BNT & & 6,35 & 5,67 & 8,78 & 12,61 & 12,75 & 12,53 & 12,31 \\
\hline
\end{tabular}

Keterangan: angka-angka sekolom yang diikuti dengan huruf yang sama dinyatakan tidak berbeda pada uji BNT $\alpha=0,05$. P0 = Kontrol, $\mathrm{P} 1=$ Aplikasi formulasi kering jamur B. bassiana konsentrasi $5 \mathrm{~g} \mathrm{l}^{-1}$ air, $\mathrm{P} 2=$ Aplikasi formulasi kering jamur B. bassiana konsentrasi $10 \mathrm{~g}^{-1}$ air, P3 = Aplikasi formulasi kering jamur B. bassiana konsentrasi $15 \mathrm{~g} \mathrm{l}^{-1}$ air, $\mathrm{P} 4=$ Aplikasi formulasi kering jamur $B$. bassiana konsentrasi $20 \mathrm{~g} \mathrm{l}^{-1}$ air, dan P5 = Aplikasi formulasi kering jamur B. bassiana konsentrasi $25 \mathrm{~g} \mathrm{l}^{-1}$ air .

Tabel 3. Periode letal jamur B. bassiana isolat Tegineneng

\begin{tabular}{cc}
\hline Perlakuan & Periode letal (hari ) \\
\hline P1 & $4,45 \mathrm{a}$ \\
P2 & $3,85 \mathrm{a}$ \\
P3 & $3,84 \mathrm{a}$ \\
P4 & $4,43 \mathrm{a}$ \\
P5 & $4,28 \mathrm{a}$ \\
\hline BNT & 0,92
\end{tabular}

Keterangan: angka-angka yang diikuti dengan huruf yang sama dinyatakan tidak berbeda pada uji BNT $\alpha=0,05$. $\mathrm{P} 0=$ Kontrol, $\mathrm{P} 1=$ Aplikasi formulasi kering jamur $B$. bassiana konsentrasi $5 \mathrm{~g}^{-1}$ air, $\mathrm{P} 2=$ Aplikasi formulasi kering jamur $B$. bassiana konsentrasi $10 \mathrm{~g} \mathrm{l}^{-1}$ air, $\mathrm{P} 3=$ Aplikasi formulasi kering jamur $B$. bassiana konsentrasi $15 \mathrm{~g} \mathrm{l}^{-1}$ air, $\mathrm{P} 4=$ Aplikasi formulasi kering jamur $B$. bassiana konsentrasi $20 \mathrm{~g}$ $\mathrm{l}^{-1}$ air, dan P5 = Aplikasi formulasi kering jamur B. bassiana konsentrasi $25 \mathrm{~g}^{\mathrm{l}^{-1}}$ air . 


\section{KESIMPULAN}

Aplikasi formulasi kering jamur B. bassiana konsentrasi $25 \mathrm{~g} \mathrm{l}^{-1}$ air menyebabkan mortalitas Helopeltis spp. sebesar 63,33\%. Nilai ini lebih tinggi dibandingkan dengan perlakuan lain dengan konsentrasi yang lebih rendah. Nilai $\mathrm{LC}_{50}$ dari formulasi kering jamur B. bassiana terhadap Helopeltis spp. adalah pada konsentrasi 22,57 $\mathrm{g} \mathrm{l}^{-1}$ air. Periode letal jamur $B$. bassiana pada seluruh perlakuan tidak berbeda berkisar antara 3,84 hari sampai 4,45 hari setelah aplikasi.

\section{DAFTAR PUSTAKA}

Amini. 2011. Keberadaan Helopeltis antonii Sebagai Hama Pada Beberapa Tanaman Perkebunan dan Pengendaliannya. Balai Besar Perbenihan dan Proteksi Tanaman Perkebunan Surabaya.

Atmadja, W.R. 2003. Status Helopeltis antonii Sebagai Hama Pada Beberapa Tanaman Perkebunan dan Pengendaliannya. J. Litbang Pertanian 22(2):57-63.

Deciyanto. 2007. Status Teknologi dan Prospek Beauveria bassiana Untuk Pengendalian Serangga Hama Tanaman Perkebunan Yang Ramah Lingkungan. Balai Penelitian Tanaman Tembakau dan Serat Malang.

Indriyati. 2009. Virulensi Jamur Entomopatogen Beauveria bassiana (Balsamo) Vuillemin Terhadap Kutu Daun (Aphis spp.) dan Kepik Hijau (Nezara Viridula). J. HPT Tropika 9(2):9298.
Negara, A. 2003. Penggunaan Analisis Probit Untuk Pendugaan Tingkat Kepekaan Populasi Spodoptera exigua Terhadap Deltametrin Di Daerah Istimewa Yogyakarta. Informatika Pertanian. $9 \mathrm{Hlm}$.

Purnomo, Aeny, T.N., dan Fitriana, Y. 2012. Pembuatan dan Aplikasi Formulasi Kering Tiga Jenis Agensia Hayati Untuk Mengendalikan Hama Pencucuk Buah dan Penyakit Busuk Buah Kakao. Laporan Penelitian Hibah Bersaing. Universitas Lampung. Bandar Lampung.

Suparno, T. 2001. Infestasi Penggerek Buah Kakao Ke dalam Perkebunan Kakao Di Kawasan Kerkap, Bengkulu Utara dan Pengendaliannya. J. HPT Tropika 1(1): 11-15.

Wahyono, T.E. 2007. Uji Patogenitas Agen Hayati Beauveria bassiana dan Metarhizium anisopliae Terhadap Ulat Serendang (Xystrocera festiva). Buletin Teknik Pertanian 12(1):27-29.

Yulyanti. 2012. Kemampuan Beberapa Isolat Beauveria bassiana (Bals.) Vuill Terhadap Mortalitas Helopeltis spp. (Skripsi). Universitas Lampung. Bandar Lampung. $51 \mathrm{hlm}$. 